\title{
The role of histone acetylation versus DNA damage in drug-induced senescence and apoptosis
}

\author{
A Rebbaa ${ }^{*, 1}, \mathrm{X}$ Zheng $^{1}, \mathrm{~F} \mathrm{Chu}{ }^{1}$ and BL Mirkin ${ }^{1,2}$ \\ ${ }^{1}$ Children's Memorial Research Center, Children's Memorial Hospital, \\ Department of Pediatrics, Northwestern University, Chicago, IL, USA \\ ${ }^{2}$ Molecular Pharmacology and Biological Chemistry, The Feinberg School of \\ Medicine, Northwestern University, Chicago, IL, USA \\ * Corresponding author: A Rebbaa, Children's Memorial Research Center, M/C \\ 224, Children's Memorial Hospital, 2300 Children's Plaza, Chicago, IL 60614, \\ USA. Tel: + 773755 6532; Fax: + 773755 6523; \\ E-mail: arebbaa@childrensmemorial.org
}

Received 06.6.05; revised 27.1.06; accepted 31.1.06; published online 24.3.06 Edited by M Oren

\begin{abstract}
The present study was undertaken to determine the significance of histone acetylation versus DNA damage in drug-induced irreversible growth arrest (senescence) and apoptosis. Cellular treatment with the DNA-damaging drugs doxorubicin and cisplatin or with the histone deacetylase inhibitor trichostatin A, led to the finding that all the three drugs induced senescence at concentrations significantly lower than those required for apoptosis. However, only doxorubicin and cisplatin induced activation of $\mathrm{H} 2 \mathrm{AX}$, a marker for double-strand break formation. Interestingly, this occurred mainly at apoptosis and not senescence-inducing drug concentrations, suggesting that non-DNA-damage pathways may be implicated in induction of senescence by these drugs. In agreement with this, chromatin immunoprecipitation experiments indicated that doxorubicin was able to induce acetylation of histone $\mathrm{H} 3$ at the promoter of p21/WAF1 only at senescence-inducing concentrations. Collectively, these findings suggest that alteration of chromatin structure by cytotoxic drugs may represent a key mediator of senescence. Cell Death and Differentiation (2006) 13, 1960-1967. doi:10.1038/sj.cdd.4401895; published online 24 March 2006
\end{abstract}

Keywords: senescence; histone acetylation; double-strand breaks; apoptosis; H2AX; p21/WAF1

Abbreviations: DSBs, DNA double-strand breaks; SA- $\beta$-Gal, senescence-associated beta galactosidase; $\gamma-\mathrm{H} 2 \mathrm{AX}$, histone $\mathrm{H} 2 \mathrm{AX}$

\section{Introduction}

Proliferation arrest and cell death are the most described biological responses to anti-cancer drugs. During the last decade, the major focus of basic research was directed towards defining the molecular pathways of apoptosis and determination of their role in chemotherapy outcome, particularly since this form of cellular demise was believed to be a key factor in the development of drug resistance. ${ }^{1}$ However, recent evidence indicates that the inhibition of apoptosis alone may not be sufficient for acquisition of the drug resistance phenotype $e^{2-4}$ and that cancer cells not only have to be viable, but must be able to proliferate in order for the tumor to progress and develop a drug-resistant phenotype. Considering that cancer cell lines with deficiencies in the apoptotic pathway can still undergo proliferation arrest as a generalized response to drugs, achieving irreversible growth arrest would be sufficient for the control of cancer progression and the prevention of drug resistance. Therefore, adequate understanding of the molecular mechanism(s) responsible for chemotherapeutic agent-induced senescence could facilitate the development of novel strategies to prevent and/or to reverse drug resistance in cancer.

Earlier investigations stressed the concept that damage to DNA constituted the primary cause of proliferation arrest and senescence in response to various stimuli. ${ }^{5}$ Upon exposure to cytotoxic drugs, cells are believed to slow down their proliferation to allow repair of damaged DNA. With the recent discovery that phosphorylation of the histone $\mathrm{H} 2 \mathrm{AX}$ $\left(\gamma-\mathrm{H}_{2} \mathrm{AX}\right)$ is associated with drug and irradiation-induced DNA double-strand breaks (DSBs), this molecule has been proposed as a mediator of DNA-damage-induced proliferation arrest. $^{6-10}$ Although this association has been observed in various cases, it does not exclude the possibility that proliferation arrest can occur independently of DNA damage. Since non-DNA targeting drugs can also inhibit proliferation, ${ }^{11-13}$ it is plausible that cellular processes other than DNA damage may activate signaling pathways leading to proliferation arrest.

Epigenetic alterations due to chromatin remodeling have been shown to play a key role in the control of cellular proliferation and response to chemotherapeutic agents. ${ }^{14,15}$ As changes in chromatin conformation may affect the binding of transcription factors and repair enzymes to DNA, the possibility exists that, whether DNA is damaged or not, gene expression may not be allowed unless chromatin is in its active state. ${ }^{16}$ Histone acetylation at the promoter region of tumor suppressor genes has been shown to induce their expression leading to the inhibition of cellular proliferation ${ }^{17}$ often through the induction of the same antiproliferative pathways that are activated by DNA damage. ${ }^{18}$ However, the question of whether chromatin remodeling and DNA damage occur concurrently or in response to different stress levels has not yet been adequately addressed.

In the present study, the relationship between DSB formation and drug-induced irreversible growth arrest and apoptosis has been investigated. Special emphasis was placed on the determination of the stress level required for the induction of each one of these cellular responses. The results demonstrated that drug-induced DSBs correlated with apoptosis and not cell proliferation arrest. In contrast, stress levels required for induction of histone acetylation correlated with the induction of cellular senescence. Our findings indicate 
that drug concentrations that induce chromatin remodeling may be sufficient for the induction of senescence.

\section{Results}

\section{Correlation between doxorubicin concentrations and the onset of proliferation arrest or cell death}

The topoisomerase inhibitor, doxorubicin, also known to act by inducing DNA double-strand breaks ${ }^{19,20}$ was utilized to define the relationship between DSB formation and the cellular responses to this drug. Incubation of the human neuroblastoma cell line SKN-SH cells with doxorubicin for up to 5 days resulted in proliferation arrest and/or cell death depending on the concentration used (Figure 1a). At concentrations less than $10^{-7} \mathrm{M}$, doxorubicin delayed cellular proliferation, and at $10^{-7} \mathrm{M}$, the cell number remained constant during the entire period of incubation suggesting irreversible growth arrest (senescence). In contrast, greater doxorubicin concentrations induced cell death.

Drug effect on the cell cycle was determined by flow cytometry (Figure 1b). The population of cells in the S-phase decreased, whereas those in the G2-M increased and reached a peak at $10^{-7} \mathrm{M}$ doxorubicin. No further accumulation of cells in the G2-M phase was observed at higher concentrations, suggesting that proliferation of most, if not all cells, was suppressed at $10^{-7} \mathrm{M}$ doxorubicin. This was associated with an increased activity of the senescenceassociated beta galactosidase (SA- $\beta$-Gal) (Figure 1c), confirming that the cells were in senescence. At a higher doxorubicin concentration $\left(10^{-6} \mathrm{M}\right)$, the cytotoxic response was apoptotic in nature as demonstrated by DNA fragmentation (Figure 1d). These findings and others from our laboratory ${ }^{3}$ provide evidence that senescence and apoptosis are induced at distinct stress levels.

\section{Molecular determinants associated with doxorubicin-induced senescence and apoptosis in SKN-SH cells}

The expression of molecular markers associated with doxorubicin-induced senescence (p21/WAF1) and apoptosis (activated caspase-3) were compared with the induction of DSBs detected by activation of $\mathrm{H} 2 \mathrm{AX}(\gamma-\mathrm{H} 2 \mathrm{AX})$. As shown in Figure $2 \mathrm{a}$, expression of $\mathrm{p} 21 / \mathrm{WAF} 1$ was maximal at $10^{-7} \mathrm{M}$ doxorubicin followed by a sharp decrease starting at $5 \times 10^{-7} \mathrm{M}$. Expression of p21/WAF1 correlated with activation of p53 at low drug concentrations but not at higher ones. However, in contrast to p21/WAF1, caspase-3 activation was detected at drug concentrations starting at $5 \times 10^{-7} \mathrm{M}$ and continued through $10^{-6} \mathrm{M}$. Of note, p53 was also detected at

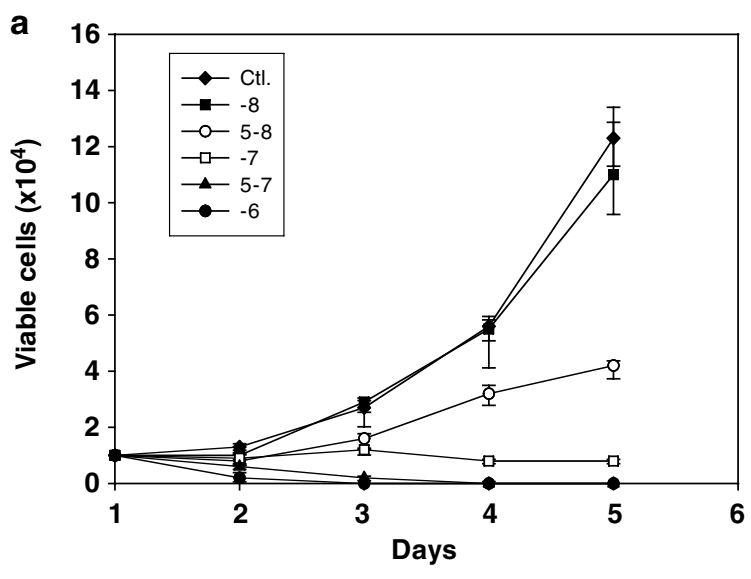

C
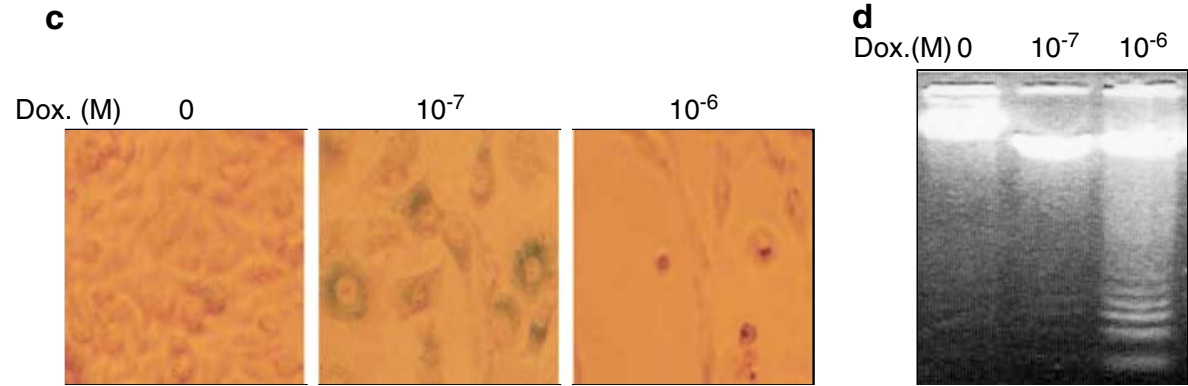

Figure 1 Induction of senescence and apoptosis by doxorubicin in SKN-SH cells. (a) Cell viability assay in response to the indicated doxorubicin concentrations was measured by MTT as described in the methods section. Data represent means of six determinations \pm S.E. (b) Flow cytometry analysis of doxorubicin-induced cell-cycle arrest. Cells were subjected to treatment with doxorubicin at the indicated concentrations (M) for $24 \mathrm{~h}$, then fixed and stained with propidium iodide, and analyzed for DNA content. Cells in the G1, S, and G2-M phases of the cell cycle are represented in the three major peaks of this diagram. (c) Cytotoxic responses associated with low and high drug concentrations. Cells incubated with $10^{-7}$ and $10^{-6} \mathrm{M}$ doxorubicin for 5 days were stained for SA-b-Gal activity to detect senescence. (d) DNA fragmentation indicative of apoptosis was also determined after $24 \mathrm{~h}$ of treatment with these two drug concentrations. Data are representative of three independent experiments 
these later drug concentrations supporting its implication in both senescence and apoptosis. These data suggested that expression of $\mathrm{p} 21 / \mathrm{WAF} 1$ and activation of caspase-3 are elements of two independent response pathways. A possible explanation for the inverse relationship between these two events could be that $\mathrm{p} 21 / \mathrm{WAF} 1$ is a putative substrate for caspase-3, as has been demonstrated previously. ${ }^{21}$ However, examination of p21/WAF1 expression by RT-PCR (Figure 2b) indicated that although this may be the case at intermediate drug concentrations (such as $5 \times 10^{-7} \mathrm{M}$ doxorubicin), high drug concentrations seemed to exert an inhibitory effect p21/WAF1expression at the message level. Overall, the data shown in Figure 2 a concur with those presented in Figure 1 indicating that doxorubicin induces primarily

a

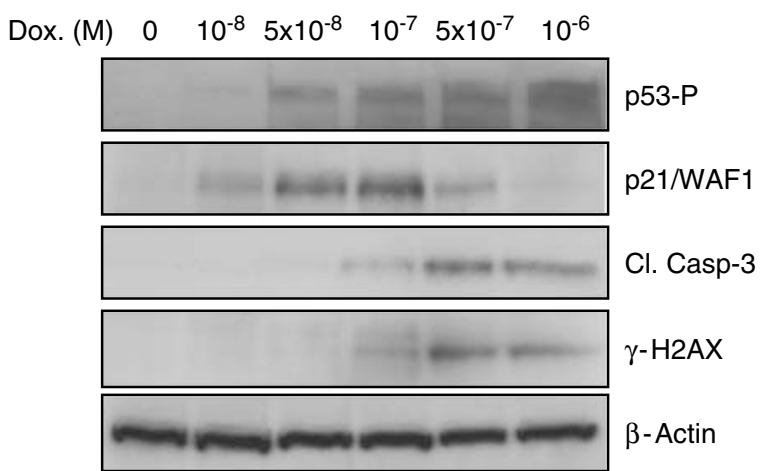

b

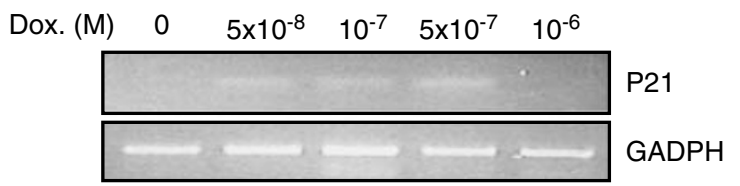

C
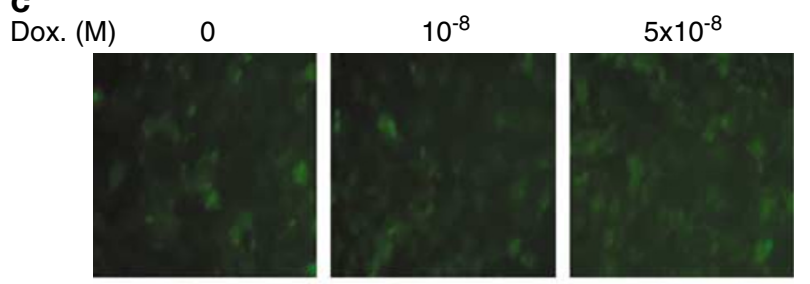

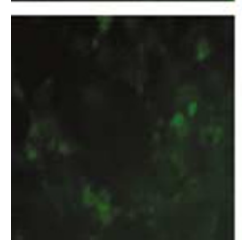

$10^{-7}$

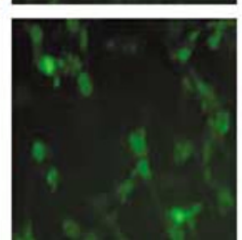

$5 \times 10^{-7}$

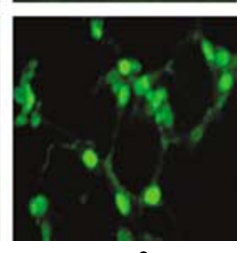

$10^{-6}$
Figure 2 Doxorubicin-induced expression of p21/WAF1 and activation of H2AX and caspase-3. (a) SKN-SH cells were treated with doxorubicin at the indicated concentrations for $24 \mathrm{~h}$. Expression of phosphorylated p53, p21/WAF1, activated (cleaved) caspase-3 (Cl. Casp-3), $\gamma-\mathrm{H} 2 \mathrm{AX}$ and $\beta$-Actin was detected by Western blot. (b) RT-PCR expression of p21/WAF1 upon exposure of cells to increasing amounts of doxorubicin using GGC AGA CCA GCA TGA CAG ATT T and GGC GGA TTA GGG CTT CCT CT as forward and reverse primers. (c) Expression of $\gamma-\mathrm{H} 2 \mathrm{AX}$ in intact cells. Cells grown on coverslips were treated for $24 \mathrm{~h}$ with doxorubicin and $\gamma-\mathrm{H} 2 \mathrm{AX}$ was detected on fixed cells using a specific antibody. Data are representative of at least three independent experiments proliferation arrest up to $10^{-7} \mathrm{M}$ and cell death at higher concentrations.

Expression of $\gamma-\mathrm{H} 2 \mathrm{AX}$ increased in response to the treatment with doxorubicin (Figure 2a) confirming that this drug was able to induce DSBs. However, this marker was detected mainly at concentrations that correlated with caspase-3 activation suggesting that DSB formation was more closely associated with cell death than with proliferation arrest. Immunohistochemical analyses carried out to detect $\gamma-\mathrm{H} 2 \mathrm{AX}$ in intact cells (Figure 2c) confirmed this observation and suggests that doxorubicin-induced DSBs may not play a major role for the induction of p21/WAF1 and proliferation arrest by this drug.

\section{Effect of doxorubicin on DNA integrity determined by the comet assay}

The apparent lack of association between expression of p21/WAF1 and activation of H2AX prompted the utilization of another analytical procedure to determine the effect of doxorubicin on DNA damage. The comet assay has been used to measure both single-strand breaks (SSBs) and DSBs. ${ }^{22}$ In this assay, doxorubicin-treated cells were electrophoresed in agarose gel and the damaged DNA that leaked from the nucleus can be visualized with the DNA intercalating agent, SyberGreen, as a fluorescent comet. Data presented in Figure $3 \mathrm{a}$ indicate that cells treated with up to $10^{-7} \mathrm{M}$ a Dox. (M) 0
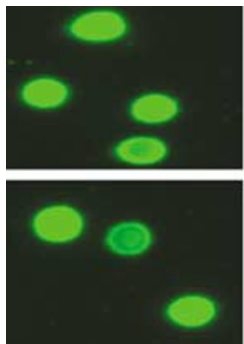

$10^{-7}$
$10^{-8}$

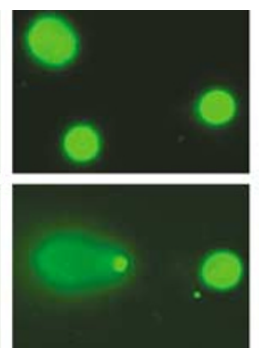

$5 \times 10^{-7}$
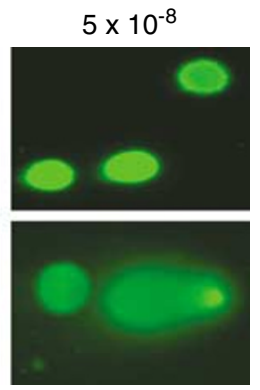

$10^{-6}$ b

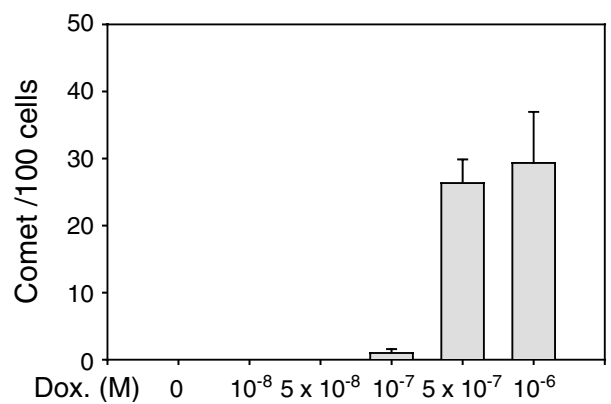

Figure 3 Measure of doxorubicin-induced DNA damage by comet assay. (a) SKN S-H cells were treated with doxorubicin for $24 \mathrm{~h}$. Single cells were then electrophoresed in agarose gel on a coverslip and stained with SyberGreen as described in the Methods section. Labeled DNA was visualized under fluorescence microscope. Cells with damaged DNA displayed a comet. (b) The number of comets per 100 cells were counted and represented as a function of drug concentration. Data represent means of three independent determinations \pm S.E. 
doxorubicin displayed a round and well-defined staining of DNA contained within the nucleus. In the presence of $5 \times 10^{-7} \mathrm{M}$ doxorubicin or higher concentrations, treated cells had a comet-like staining indicating that DNA has been damaged. Interestingly, not more than $30 \%$ of cells treated with high doxorubicin concentrations displayed the comet pattern (Figure $3 b$ ). The later finding suggests that these types of DNA damage may not be the only cause of cell death and that induction of apoptosis in a DNA damage-independent manner may also account for cell killing. Nevertheless, the results presented demonstrated that doxorubicin-induced SSBs and/or DSBs were detected only at drug concentrations greater than those required for proliferation arrest.

\section{Validation for other drugs and cell types}

Cisplatin, a widely known DNA alkylating drug and inducer of DSBs, ${ }^{23}$ was used to verify whether the findings described above, applied to other DNA-damaging drugs. As shown in Figure $4 \mathrm{a}$, expression profiles of p21/WAF1, cleaved caspase-3 and activated $\mathrm{H} 2 \mathrm{AX}$ in response to cisplatin in $\mathrm{SKN}$ $\mathrm{SH}$ cells were very similar to those induced by doxorubicin in the same cells (Figure 2a). Moreover, expression profiles of these markers in the human glioma cell line U251 with either doxorubicin (Figure 4b) or cisplatin (Figure 4c) were also identical to those obtained with SKN-SH in response to these drugs (Figures $2 a$ and $4 a$ ) suggesting that this type of cellular response may occur with other drugs and in other cell lines.

\section{Relationship between stress level and incubation time required for the induction of senescence DSBs, and apoptosis}

Experiments were undertaken to determine whether prolonged incubation with a senescence-inducing doxorubicin concentration $\left(10^{-7} \mathrm{M}\right)$ could ultimately result in DSB formation. As shown in Figure 5a, in response to such treatment, the level of p21/WAF1 was sustained for up to 5 days and there was no detectable activation of $\mathrm{H} 2 \mathrm{AX}$ during this incubation period. When the cells were subjected to an apoptosisinducing doxorubicin concentration $\left(10^{-6} \mathrm{M}\right)$, a rapid activation of $\mathrm{H} 2 \mathrm{AX}$ was observed, as early as $1 \mathrm{~h}$, whereas that of caspase- 3 was initiated between 6 and $24 \mathrm{~h}$ (Figure 5b). This finding suggested that activated $\mathrm{H} 2 \mathrm{AX}$ may be an early event in the apoptotic pathway initiated by exposure to DNAdamaging drugs. Overall, these data further confirm the lack of association between DSBs and proliferation arrest and suggest that this type of damage may signal primarily for apoptotic cell death.

\section{Effect of the non-DNA damaging drug Trichostatin $A$ on proliferation arrest and apoptosis}

As DSBs appeared to be unlikely mediators of doxorubicin or cisplatin induction of p21/WAF1 and cellular senescence at least in the cellular models used in this study, we asked the question of what could be the cause. Recent reports have shown that histone deacetylase inhibitors (HDACls) induce senescence via activation of cell-cycle inhibitors such as p16/
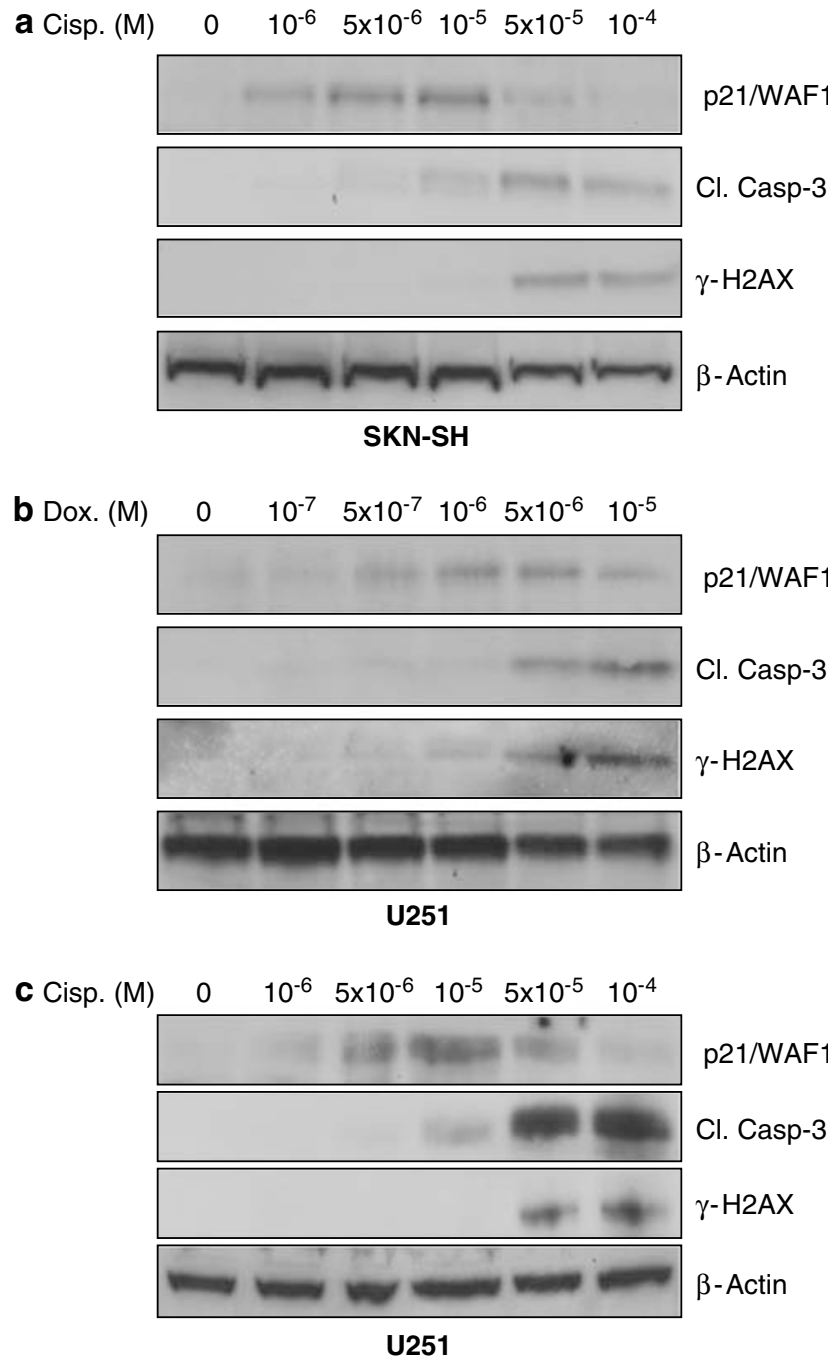

Figure 4 Effect of doxorubicin and cisplatin on expression of p21/WAF1, cleaved caspase-3 and $\gamma-\mathrm{H} 2 \mathrm{AX}$ in neuroblastoma (SKN-SH) and glioma (U251) cell lines. SKN-SH cells were treated with cisplatin (a) and U251 cells were incubated with either doxorubicin (b) or cisplatin (c) for $24 \mathrm{~h}$. Expression of the above molecular markers was detected by Western blot. Expression of $\beta$-Actin was used as gel-loading control

INK4. ${ }^{24}$ We used a deacetylase inhibitor, trichostatin A (TSA), to determine its effect on cellular proliferation, the expression of p21WAF1 and the activation of caspase-3. As shown in Figure $6 \mathrm{a}$, depending on the concentration used, TSA caused either proliferation arrest or cell death. This drug appeared to induce a G2/M cell-cycle arrest (Figure 6b) with features of senescence as shown by changes in cell morphology and activity of the SA- $\beta$-Gal (Figure 6b, insert). As TSA affects primarily the chromatin structure, no DNA double-strand breaks, represented by $\gamma-\mathrm{H} 2 \mathrm{AX}$, were detected even at high drug concentrations (Figure $6 \mathrm{c}$ ). However, similar to doxorubicin and cisplatin, cellular treatment with TSA led to the activation of p53 and induction of p21/WAF1 followed by activation of caspase-3, suggesting that changes in chromatin structure induced by this drug may act as a signal for both cellular responses. 
a
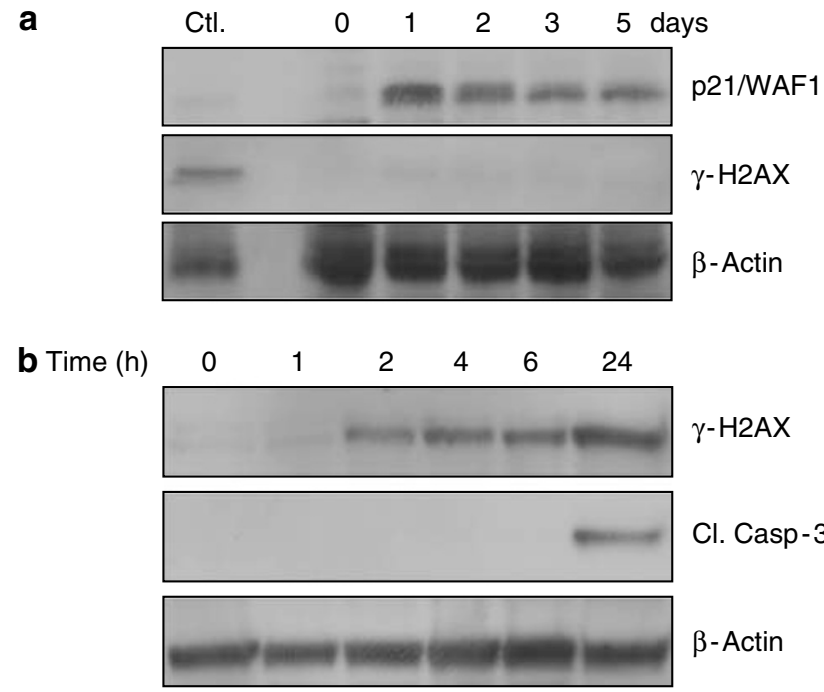

Figure 5 Kinetics of doxorubicin-induced expression of p21/WAF1 and activation of $\gamma-\mathrm{H} 2 \mathrm{AX}$ and caspase-3. (a) SKN-SH cells were incubated with doxorubicin concentration $\left(10^{-7} \mathrm{M}\right)$ for up to 5 days. Expression of p21/WAF1 was compared to activation of $\mathrm{H} 2 \mathrm{AX}$ by Western blot using specific antibodies. $\mathrm{Ctl}$. Represents a positive control for activated H2AX. Expression of $\beta$-Actin was used as a loading control. (b) The cells were exposed to apoptosis-inducing drug concentration $\left(10^{-6} \mathrm{M}\right)$ for up to $24 \mathrm{~h}$ and expression of the above molecules was detected as in (a). Data are representative of three independent experiments

\section{Correlation between doxorubicin-induced histone acetylation and p21/WAF1 expression}

To determine whether low concentrations of doxorubicin that induce p21/WAF1 expression also affect chromatin structure, we examined the status of histone acetylation by using a polyclonal antibody that recognizes acetylated histone $\mathrm{H} 3$ at lysine 9. As shown in Figure $7 \mathrm{a}$, there was a strong association between acetylation of this histone and p21/ WAF1 expression. In contrast, these events were inversely correlated with activation of $\mathrm{H} 2 \mathrm{AX}$. This could be explained by the fact that if DSBs signal for caspase activation and apoptosis, histone acetylases may represent potential substrates for caspases.

To determine whether histone acetylation was altered at the promoter region of p21/WAF1, we utilized the chromatin immunoprecipitation assay $(\mathrm{Chlp}) .{ }^{25}$ This procedure revealed that histone acetylation occurred essentially at drug concentrations affecting cellular proliferation but not cell death (Figure $7 \mathrm{~b}$ ). Even within the same promoter, the sequence surrounding $-105 \mathrm{bp}$ site appeared to be more sensitive to changes in stress levels than that surrounding the -2760 site. This supported other findings in this study (See Figure 7a) and suggested that doxorubicin-induced chromatin acetylation at the promoter region of $\mathrm{p} 21 / \mathrm{WAF} 1$ may act to increase its expression and facilitate proliferation arrest. a
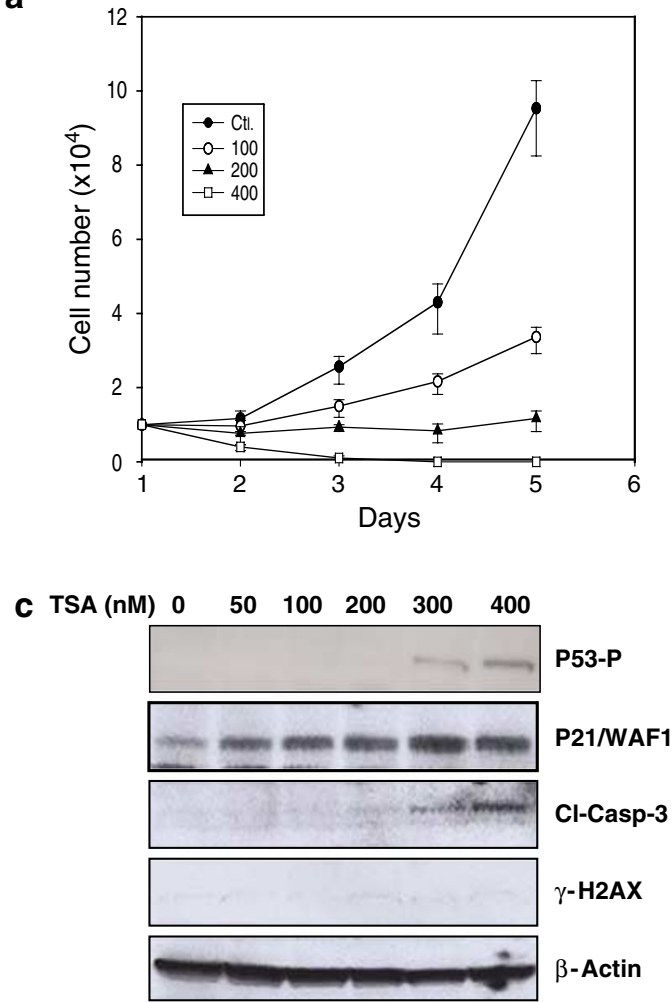

b
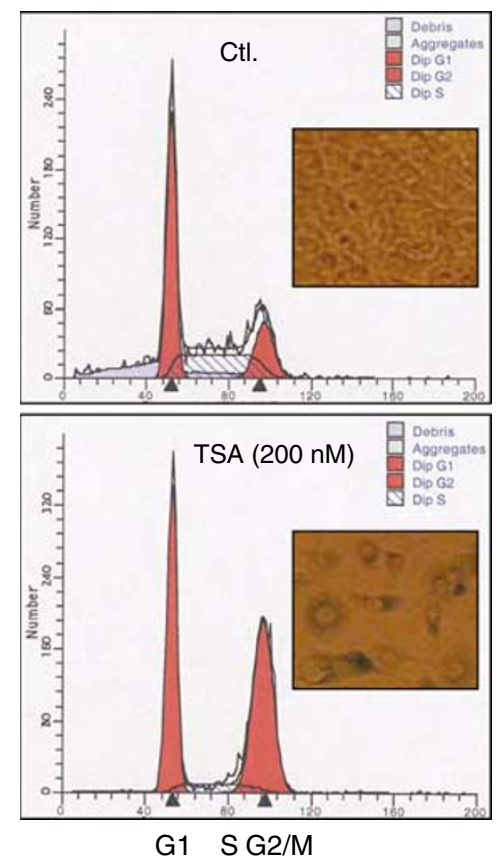

G1 S G2/M

Figure 6 Induction of proliferation arrest and cell death by trichostatin A (TSA). (a) SKN-SH cells were treated with the indicated concentrations of TSA (nM) and cell number was counted for up to 5 days. (b) FACS analysis of the effect of TSA on cellular distribution in the cell cycle after $24 \mathrm{~h}$ incubation. The inserts show a representative senescence-associated beta galactosidase (SA- $\beta$-Gal) staining upon cellular incubation with or without TSA for 5 days. (c) Expression of activated P53 (p53-P), p21/WAF1, Cleaved caspase-3 (Cl-casp3) and $\gamma \mathrm{H} 2 \mathrm{AX}$ were determined by Western blot after treatment with doxorubicin for $24 \mathrm{~h}$. The data is representative of three independent experiments 
a

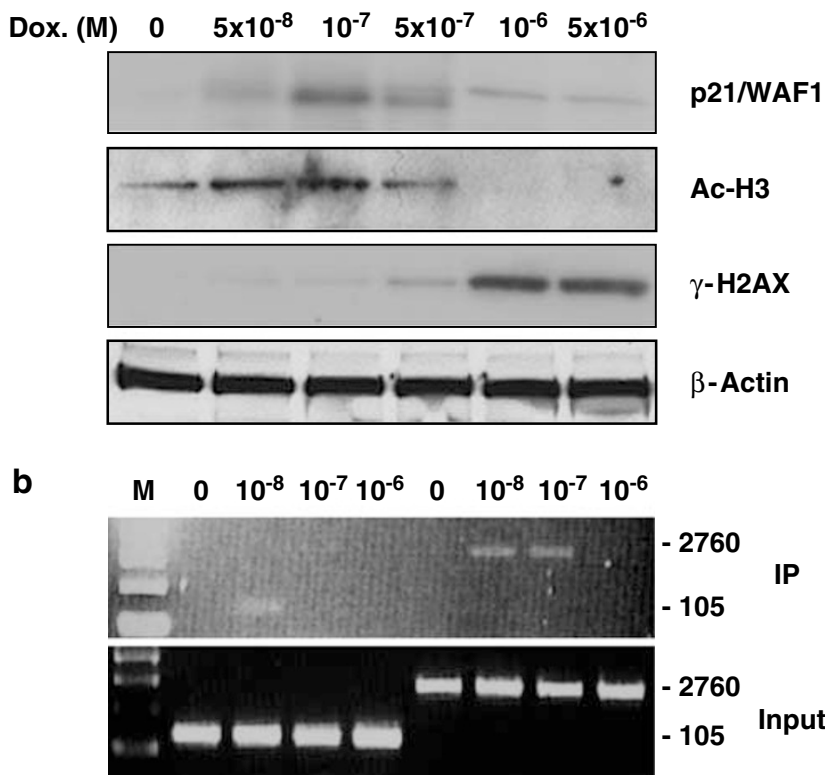

Figure 7 Effect of doxorubicin on histone acetylation. (a) SKN-SH cells were exposed to doxorubicin at the indicated concentrations for $24 \mathrm{~h}$ and expression of p21/WAF1, acetylated histone $\mathrm{H} 3(\mathrm{Ac}-\mathrm{H} 3), \gamma \mathrm{H} 2 \mathrm{AX}$ and $\beta$-actin were determined by Western blot. (b) Chromatin immunoprecipitation assay showing enhanced histone acetylation at the p21/WAF1 promoter region. After treatment with doxorubicin for $24 \mathrm{~h}$, chromatin was immunoprecipitated and the associated DNA extracted and amplified with PCR primers corresponding to two different segments of the p21/WAF1 promoter $(-105$ and $-2760 \mathrm{bp})$. The 'Input' indicates amplified DNA sequences before chromatin immunoprecipitation

\section{Discussion}

The role of senescence in cancer chemotherapy and particularly in the development of drug resistance has become increasingly evident, leading to interest in defining the mechanism(s) by which chemotherapeutic agents induce this response. DNA damage in response to cytotoxic drugs has been frequently described as the principal regulator of proliferation arrest, cellular senescence and apoptosis. However, recently, it has become recognized that changes in chromatin remodeling can induce similar responses in a DNA-damage independent manner. In the present study we have investigated the role of DNA damage versus histone acetylation in induction of senescence and the effect of drug dosage in targeting either histones or DNA. This has been addressed by comparing the occurrence of DNA damage, expression of markers of proliferation arrest and extent of cell death in response to DNA-damaging and non-damaging drugs.

The ability to distinguish between the stress levels required for senescence and apoptosis (Figures 1 and 2), ${ }^{3,4}$ makes it possible to investigate whether DNA damage was part of the signaling pathway leading to one or the other of these cellular demises. If it associated with senescence, H2AX activation by a DNA-damaging drug must occur with lower or at least equivalent drug amounts to that required for the induction of p21/WAF1. The data presented in Figures 2 and 3 revealed that this was not the case and that activation of $\mathrm{H} 2 \mathrm{AX}$ required much higher drug concentrations than those needed for the induction of p21/WAF1. Instead, activation of H2AX appeared to be associated with that of caspase-3 (Figures 2 and 4) suggesting that this molecule may represent an essential signal for apoptosis. ${ }^{26}$ The rapid activation of $\mathrm{H} 2 \mathrm{AX}$, compared to caspase-3 in response to doxorubicin (Figure $5 b$ ) further confirmed this hypothesis and suggested that DSBs may represent an early event in drug-mediated apoptosis.

A significant finding of this investigation was that histone acetylation at the promoter region of $\mathrm{p} 21 / \mathrm{WAF} 1$ may mediate doxorubicin-induced expression of this cell-cycle inhibitor and cellular senescence. In addition, as the histone deacetylase inhibitor TSA was able to induce senescence despite the absence of DNA damage (Figure 6), it is suggested that DNAdamaging drugs may induce senescence in a DNA damageindependent manner. Data presented in Figure 7a appeared to validate this hypothesis and indicated that histones were more sensitive to stress than DNA. Chromatin acetylation is known to result in its decondensation, thus facilitating access of transcription machinery to the promoter regions of tumor suppressor genes. ${ }^{27}$ Chromatin immunoprecipitation results (Figure 7b) demonstrated that depending on the stress level, DNA damaging drugs can induce histone acetylation and induction of the tumor suppressor p21/WAF1 without significant induction of DNA damage.

In conclusion, the present study suggests that although treatment of cancer cells with chemotherapeutic agents elicited the generation of DSBs at higher concentrations, alteration in histone acetylation appeared to be the key mediator of proliferation arrest at low stress levels. We propose that depending on concentrations, the nature of drug targets may change and that histones may be more sensitive to low stress levels than DNA.

\section{Materials and Methods}

\section{Reagents}

Human neuroblastoma SKN-SH and glioma U251 cell lines were purchased from ATCC (ATCC, Rockville MA, USA). Dulbecco's Modified Eagle's Medium (DMEM) and fetal bovine serum (FBS) were obtained from BioWhittaker (Walkersville, MD, USA). Doxorubicin, 3-(4,5-dimethyl2-thiazolyl)2,5-diphenyl tetrazolium bromide (MTT), cisplatin, and 5bromo-4-chloro-3-indolyl beta-D-galactopyranoside (X-Gal), and protein A agarose were purchased from Sigma (St. Louis, MO, USA). Antibodies to p21/WAF1 and to $\beta$-actin were obtained from Santa Cruz Biotechnologies (Santa Cruz, CA), antibodies to phosphorylated p53, cleaved caspase-3 and secondary antibodies conjugated to horseradish peroxidase from Cell Signaling Technologies (Beverly, MA, USA). Antibody to $\gamma-\mathrm{H} 2 \mathrm{AX}$ and to acetylated histone $\mathrm{H} 3$ (K9) were purchased from Upstate Cell signaling Solutions (Lake Placid, NY). Enhanced chemiluminescence reagents (ECL) were from Amersham (Arlington Heights, IL). Immobilon-P transfer membrane for Western blots was purchased from Millipore (Bedford, MA, USA).

\section{Cell culture, drug treatment and cytotoxicity assay}

Cells were cultured in DMEM supplemented with $10 \%$ FBS at $37^{\circ} \mathrm{C}$ in a $95 \%$ Air $/ 5 \% \mathrm{CO}_{2}$ atmosphere. Cytotoxic activity of doxorubicin was quantitatively determined by a colorimetric assay utilizing 3-(4,5-dimethyl-2-thiazolyl) 
2,5-diphenyl tetrazolium bromide (MTT), as described previously. ${ }^{28}$ Briefly, cells were seeded at $10^{4}$ cells/well in 96-well plates and maintained in culture for $24 \mathrm{~h}$ at $37^{\circ} \mathrm{C}$ in DMEM supplemented with $10 \% \mathrm{FBS}$. The drug was added to designated wells and incubated for $72 \mathrm{~h}$, following which MTT ( $10 \mu \mathrm{l}$ of $5 \mathrm{mg} / \mathrm{ml}$ solution) was added to each well $(100 \mu \mathrm{l})$ and incubated for $4 \mathrm{~h}$ at $37^{\circ} \mathrm{C}$. The cells were solubilized by incubation with $100 \mu \mathrm{l}$ of $\mathrm{HCl}$ $0.5 \mathrm{~N} /$ isopropanol for $15 \mathrm{~h}$ at $37^{\circ} \mathrm{C}$. The optical density of this solution was measured at $570 \mathrm{~nm}$ and the percentage of viable cells estimated by comparison with untreated control cells.

\section{Western-blot analysis}

Cells were seeded in $75 \mathrm{~cm}^{2}$ flasks in DMEM containing 10\% FBS and cultivated for $24 \mathrm{~h}$ before addition of the drug. After incubation for an additional $24 \mathrm{~h}$, cells were pelleted and washed with TBS and resuspended in buffer A (10 mM HEPES pH 7.9, 0.1 mM EDTA, $10 \mathrm{mM} \mathrm{KCL}$, 0.1 EGTA, $1 \mathrm{mM}$ DTT, $0.5 \mathrm{mM}$ PMSF). The mixture was incubated for $30 \mathrm{~min}$ on ice then $25 \mu \mathrm{l}$ of $10 \%$ Nonidet P-40 was added and the homogenate centrifuged for $30 \mathrm{~s}$. The nuclear pellet was re-suspended in $50 \mu$ l of ice-cold buffer $\mathrm{B}$ ( $20 \mathrm{mM}$ HEPES pH 7.9, $0.4 \mathrm{M} \mathrm{NaCl}, 1 \mathrm{mM}$ EDTA, $1 \mathrm{mM}$ EGTA, $1 \mathrm{mM}$ DTT, $1 \mathrm{mM}$ PMSF). The samples were then incubated at $4{ }^{\circ} \mathrm{C}$ for $30 \mathrm{~min}$ and centrifuged at $12000 \times \mathrm{g}$ for $5 \mathrm{~min}$. The supernatant containing the nuclear extract was processed by Western blot for detection of p21/WAF1, and activated H2AX. The cytoplasmic fractions were processed for detection of cleaved caspase- 3 and $\beta$ actin. Equal quantities of protein were separated by electrophoresis on a $12 \%$ SDS-PAGE gel and transferred to Immobilon-P membranes. Proteins of interest were identified by reaction with specific primary and secondary antibodies linked to horseradish peroxidase. Reactive bands were detected by chemiluminescence. ${ }^{3}$

\section{Flow cytometry}

SKN-SH cells (about $10^{6}$ ) were incubated with various concentrations of doxorubicin for $24 \mathrm{~h}$, then collected by trypsinization and washed twice with PBS containing $5 \mathrm{mM}$ EDTA. Cells were fixed in $70 \%$ ethanol and incubated for $10 \mathrm{~min}$ on ice. Before flow cytometry analysis, cells were washed twice with PBS/5 mM EDTA and subjected to treatment with RNAse A $\left(2 \mu \mathrm{g} / \mathrm{ml}\right.$ of PBS) for $30 \mathrm{~min}$ at $37^{\circ} \mathrm{C}$. The cells were then incubated with propidium iodide $(10 \mu \mathrm{g} / \mathrm{ml})$ for $1 \mathrm{~h}$ at room temperature, filtered and DNA content analyzed by flow cytometry.

\section{Senescence associated- $\beta$-Galactosidase (SA- $\beta$-Gal) staining}

Cells were seeded into 24-well plates in DMEM culture medium and after $24 \mathrm{~h}$, doxorubicin or TSA were added and the cells incubated for 5 days. SA- $\beta$-Gal staining was performed as previously described. ${ }^{29}$ In brief, cells were fixed for $5 \mathrm{~min}$ in $3 \%$ formaldehyde, washed and incubated at $37^{\circ} \mathrm{C}$ with X-gal $(1 \mathrm{mg} / \mathrm{ml})$, dissolved in a solution containing $40 \mathrm{mM}$ citric acid $\mathrm{pH} 6.5,5 \mathrm{mM}$ potassium ferrocyanide, $5 \mathrm{mM}$ potassium ferricyanide, $150 \mathrm{mM} \mathrm{NaCl}$, and $2 \mathrm{mM} \mathrm{MgCl}_{2}$. After $24 \mathrm{~h}$ incubation, photographs were taken under a phase microscope.

\section{Measure of DNA fragmentation}

Cells were incubated with doxorubicin at various concentrations for $24 \mathrm{~h}$ at $37^{\circ} \mathrm{C}$ and DNA prepared from Triton X-100 lysates for analysis of fragmentation. Briefly, cells were lysed in a hypotonic solution containing
$10 \mathrm{mM}$ Tris $\mathrm{HCl}(\mathrm{pH} 7.4), 1 \mathrm{mM}$ EDTA, and $0.2 \%$ Triton $\mathrm{X}-100$, and centrifuged at $11000 \times g$ for $5 \mathrm{~min}$. Supernatants were electrophoresed on a $1 \%$ agarose gel and DNA fragments visualized under UV light after staining with ethidium bromide.

\section{Comet assay}

This single-cell electrophoresis assay is used for evaluating the formation of both single-strand and double-strand breaks following cell exposure to DNA damaging agents. ${ }^{22}$ After drug treatment, cells $\left(10^{5} \mathrm{cell} / \mathrm{ml}\right)$ were washed twice with PBS and mixed at a ratio 1:10 (v/v) with LMA agarose (Trevigen, Gaithensburg, MD, USA) at $37^{\circ} \mathrm{C}$. A $75 \mu \mathrm{l}$ aliquot of the cell suspension was spotted on a microscope slide and maintained at $4^{\circ} \mathrm{C}$ for $30 \mathrm{~min}$ to allow polymerization of the gel. The cells were then lysed in a solution containing $2.5 \mathrm{M} \mathrm{NaCl}, 100 \mathrm{mM}$ EDTA, $10 \mathrm{mM}$ Tris $(\mathrm{pH} 10)$ and $1 \%$ Triton-X100, followed by incubation in alkali conditions $(300 \mathrm{mM}$ $\mathrm{NaOH}, 1 \mathrm{mM}$ EDTA) for $1 \mathrm{~h}$ at room temperature to allow DNA unwinding and expression of SSBs and DSBs. The slides were then placed in a horizontal electrophoresis system and subjected to a $1 \mathrm{~V} / \mathrm{cm}$ current for $15 \mathrm{~min}$. They were then exposed for $5 \mathrm{~min}$ to absolute ethanol and subsequently air-dried. Just before comet scoring, the DNA was stained with SyberGreen $(1 \mu \gamma / \mathrm{ml} 50 \mu \mathrm{l} / \mathrm{slide})$, and viewed by fluorescence microscopy (excitation $494 \mathrm{~nm}$, emission $521 \mathrm{~nm}$ ).

\section{Chlp assay}

Cells were seeded in $25 \mathrm{~cm}^{2}$ flasks and when they had reached $60 \%$ confluency, doxorubicin was added and incubated for times varying from 1 to $24 \mathrm{~h}$. Chromatin immunoprecipitation was carried out by using the Chlp Assay kit \#17-295 (Upstate Cell Signaling Solutions, Lake Placid, NY, USA). The cells were lysed in SDS lysis buffer provided in the kit and cell lysate sonicated to shear DNA into 100-200 base pairs. Anti-acetyl histone H3 (K9) and Salmon sperm DNA/ProteinA agarose were utilized to immunoprecipitate chromatin fragments. DNA was then extracted from the immunoprecipitate and amplified by PCR using the following: ${ }^{25}$ region $-105 /+25$ of the p21/WAF1 promoter spanning the TATA box of the promoter 5'-GCGGCGCGGTGG GCCGAGCGCGGG-3' (Forward primer), 5'-GGCTCCACAAGGAACTGACT-3' (Backward primer). Region $-2760 /-2486$ of the p21/WAF1 promoter 5'TTGTGCCACTGCTGA CTTTGTC-3' (Forward primer), 5'-AGCCTGAAGAAGGAGGATGT GAGG-3' (Backward primer). Amplification was carried out for 35 cycles under the cycling conditions described previously. ${ }^{25}$

\section{Acknowledgements}

This study is supported in part by the National Cancer Institute (1R01 CA096616-01A1 to AR), the Illinois Department of Public Aid (AR), the North Suburban Medical Research Junior Board (AR and BLM), the Anderson Foundation (BLM), the Medical Research Institute Council (BLM), and R Wile Neuroblastoma and Chemotherapy Fund (BLM). We thank Roberta Gerard and Sandra Clark for their assistance in the preparation of this manuscript.

\section{References}

1. Pommier $Y$, Sordet $\mathrm{O}$, Antony S, Hayward RL and Kohn KW (2004) Apoptosis defects and chemotherapy resistance: molecular interaction maps and networks. Oncogene 23: 2934-2949. 
2. Brown JM and Wouters BG (1999) Apoptosis, p53, and tumor cell sensitivity to anticancer agents. Cancer Res. 59: 1391-1399.

3. Rebbaa A, Zheng X, Chou PM and Mirkin BL (2003) Caspase inhibition switches doxorubicin-induced apoptosis to senescence. Oncogene 22: 28052811.

4. Zheng X, Chou PM, Mirkin BL and Rebbaa A (2004) Senescence-initiated reversal of drug resistance: specific role of cathepsin L. Cancer Res. 64: 1773-1780.

5. Durocher D and Jackson SP (2001) DNA-PK, ATM and ATR as sensors of DNA damage: variations on a theme? Curr. Opin. Cell Biol. 13: 225-231.

6. Celeste A, Fernandez-Capetillo O, Kruhlak MJ, Pilch DR, Staudt DW, Lee A, Bonner RF, Bonner WM and Nussenzweig A (2003) Histone H2AX phosphorylation is dispensable for the initial recognition of DNA breaks. Nat. Cell Biol. 5: 675-679.

7. Holmes AM and Haber JE (1999) Double-strand break repair in yeast requires both leading and lagging strand DNA polymerases. Cell 96: $415-424$.

8. Huang X, Okafuji M, Traganos F, Luther E, Holden E and Darzynkiewicz Z (2004) Assessment of histone H2AX phosphorylation induced by DNA topoisomerase I and II inhibitors topotecan and mitoxantrone and by the DNA cross-linking agent cisplatin. Cytometry 58A: 99-110.

9. Khanna KK and Jackson SP (2001) DNA double-strand breaks: signaling, repair and the cancer connection. Nat. Genet. 27: 247-254.

10. Rogakou EP, Pilch DR, Orr AH, Ivanova VS and Bonner WM (1998) DNA double-stranded breaks induce histone $\mathrm{H} 2 \mathrm{AX}$ phosphorylation on serine 139 . J. Biol. Chem. 273: 5858-5868.

11. Wisniewski D, Lambek CL, Liu C, Strife A, Veach DR, Nagar B, Young MA Schindler T, Bornmann WG, Bertino JR, Kuriyan J and Clarkson B (2002) Characterization of potent inhibitors of the Bcr-Abl and the c-kit receptor tyrosine kinases. Cancer Res. 62: 4244-4255.

12. Yokota T, Matsuzaki Y, Miyazawa K, Zindy F, Roussel MF and Sakai T (2004) Histone deacetylase inhibitors activate INK4d gene through Sp1 site in its promoter. Oncogene 23: 5340-5349.

13. Zhu K, Gerbino E, Beaupre DM, Mackley PA, Muro-Cacho C, Beam C Hamilton AD, Lichtenheld MG, Kerr WG, Dalton W, Alsina M and Sebti SM (2005) Farnesyltransferase inhibitor R115777 (Zarnestra, Tipifarnib) synergizes with paclitaxel to induce apoptosis and mitotic arrest and to inhibit tumor growth of multiple myeloma cells. Blood.

14. Cairns BR (2001) Emerging roles for chromatin remodeling in cancer biology. Trends Cell Biol. 11: S15-S21.

15. Baker EK and El-Osta A (2004) MDR1, chemotherapy and chromatin remodeling. Cancer Biol. Ther. 3: 819-824.

16. Bassal S and El-Osta A (2005) DNA damage detection and repair, and the involvement of epigenetic states. Hum. Mutat. 25: 101-109.

17. Lagger G, Doetzlhofer A, Schuettengruber B, Haidweger E, Simboeck $E$, Tischler J, Chiocca S, Suske G, Rotheneder H, Wintersberger E and Seiser C
(2003) The tumor suppressor p53 and histone deacetylase 1 are antagonistic regulators of the cyclin-dependent kinase inhibitor p21/WAF1/CIP1 gene. Mol. Cell. Biol. 23: 2669-2679.

18. Gui CY, Ngo L, Xu WS, Richon VM and Marks PA (2004) Histone deacetylase (HDAC) inhibitor activation of p21WAF1 involves changes in promoterassociated proteins, including HDAC1. Proc. Natl. Acad. Sci. USA 101: 12411246.

19. Binaschi M, Capranico G, Dal Bo L and Zunino F (1997) Relationship between lethal effects and topoisomerase II-mediated double-stranded DNA breaks produced by anthracyclines with different sequence specificity. Mol. Pharmacol. 51: 1053-1059.

20. Duran GE, Lau DH, Lewis AD, Kuhl JS, Bammler TK and Sikic BI (1996) Differential single- versus double-strand DNA breakage produced by doxorubicin and its morpholinyl analogues. Cancer Chemother. Pharmacol. 38: 210-216

21. Jin YH, Yoo KJ, Lee YH and Lee SK (2000) Caspase 3-mediated cleavage of p21WAF1/CIP1 associated with the cyclin A-cyclin-dependent kinase 2 complex is a prerequisite for apoptosis in SK-HEP-1 cells. J. Biol. Chem. 275: 30256-30263

22. Garry S, Nesslany F, Aliouat E, Haguenoer JM and Marzin D (2003) Assessment of genotoxic effect of benzo[a]pyrene in endotracheally treated rat using the comet assay. Mutat. Res. 534: 33-43.

23. Ormerod MG, O'Neill CF, Robertson D and Harrap KR (1994) Cisplatin induces apoptosis in a human ovarian carcinoma cell line without concomitant internucleosomal degradation of DNA. Exp. Cell Res. 211: 231-237.

24. Munro J, Barr NI, Ireland H, Morrison V and Parkinson EK (2004) Histone deacetylase inhibitors induce a senescence-like state in human cells by a p16dependent mechanism that is independent of a mitotic clock. Exp. Cell Res. 295: 525-538

25. Giraud S, Hurlstone A, Avril S and Coqueret $O$ (2004) Implication of BRG1 and cdk9 in the STAT3-mediated activation of the p21waf1 gene. Oncogene 23: 7391-7398.

26. Kaina B (2003) DNA damage-triggered apoptosis: critical role of DNA repair, double-strand breaks, cell proliferation and signaling. Biochem. Pharmacol. 66: 1547-1554.

27. Siddiqui $H$, Solomon DA, Gunawardena RW, Wang $Y$ and Knudsen ES (2003) Histone deacetylation of RB-responsive promoters: requisite for specific gene repression but dispensable for cell cycle inhibition. Mol. Cell. Biol. 23: 7719-7731.

28. Rebbaa A, Chou PM and Mirkin BL (2001) Factors secreted by human neuroblastoma mediated doxorubicin resistance by activating STAT3 and inhibiting apoptosis. Mol. Med. 7: 393-400.

29. Dimri GP, Lee X, Basile G, Acosta M, Scott G, Roskelley C, Medrano EE, Linskens M, Rubelj I, Pereira-Smith O, Peacoke M and Campisi J (1995) A biomarker that identifies senescent human cells in culture and in aging skin in vivo. Proc. Natl. Acad. Sci. USA 92: 9363-9367. 